\title{
Derivation and validation of a clinical decision rule to identify young children with skull fracture following isolated head trauma
}

\author{
Jocelyn Gravel MD MSc, Serge Gouin MDCM, Dominic Chalut MD, Louis Crevier MD MSc, \\ Jean-Claude Décarie MD, Nicolas Elazhary MD, Benoît Mâsse PhD
}

CMAJ Podcasts: author interview at https://soundcloud.com/cmajpodcasts/150540-res

See also page 1189 and www.cmaj.ca/lookup/doi/10.1503/cmaj.150949

Competing interests: None declared.

This article has been peer reviewed.

Accepted: July 30, 2015 Online: Sept. 8, 2015

Correspondence to: Jocelyn Gravel, graveljocelyn@hotmail.com

CMAJ 2015. DOI:10.1503/ cmaj.150540

\begin{abstract}
Background: There is no clear consensus regarding radiologic evaluation of head trauma in young children without traumatic brain injury. We conducted a study to develop and validate a clinical decision rule to identify skull fracture in young children with head trauma and no immediate need for head tomography.
\end{abstract}

Methods: We performed a prospective cohort study in 3 tertiary care emergency departments in the province of Quebec. Participants were children less than 2 years old who had a head trauma and were not at high risk of clinically important traumatic brain injury (Glasgow Coma Scale score < 15, altered level of consciousness or palpable skull fracture). The primary outcome was skull fracture. For each participant, the treating physician completed a standardized report form after physical examination and before radiologic evaluation. The decision to order skull radiography was at the physician's discretion. The clinical decision rule was derived using recursive partitioning.

Results: A total of 811 patients (49 with skull fracture) were recruited during the derivation phase. The 2 predictors identified through recursive partitioning were parietal or occipital swelling or hematoma and age less than 2 months. The rule had a sensitivity of $94 \%$ (95\% confidence interval $[\mathrm{Cl}] 83 \%-99 \%$ ) and a specificity of $86 \%(95 \% \mathrm{Cl} 84 \%-89 \%)$ in the derivation phase. During the validation phase, 856 participants (44 with skull fracture) were recruited. The rule had a sensitivity of $89 \%$ and a specificity of $87 \%$ during this phase.

Interpretation: The clinical decision rule developed in this study identified about $90 \%$ of skull fractures among young children with mild head trauma who had no immediate indication for head tomography. Use of the rule would have reduced the number of radiologic evaluations by about $60 \%$.
$\mathrm{H}$ ead trauma is common among children visiting the emergency department and in most cases is minor. ${ }^{1}$ However, socalled "minor" head trauma can be associated with dangerous complications. For example, $6 \%$ to $30 \%$ of children less than 2 years of age with head trauma present with a skull fracture. ${ }^{2-7}$ The risk of an intracranial hematoma is about 12 times higher among patients with a skull fracture than among other patients..$^{8-11}$ Skull fracture may also be complicated by leptomeningeal cyst, ${ }^{12}$ growing fracture ${ }^{13}$ or displaced fracture. ${ }^{14}$ Even though growing fracture is uncommon ( $2 \%$ of all fractures), its detection is important because of the risk of brain hernia if left undiscovered. ${ }^{13,15-17}$
Rapid identification can lead to successful repair with a rather simple neurosurgical intervention. ${ }^{18}$

Controversies exist regarding the proper use of radiology for minor head trauma in children. Whereas some national guidelines suggest a wide spectrum of criteria to perform a radiologic evaluation, others are strict. ${ }^{19-22}$ Large, well-conducted studies have identified predictive criteria of clinically important traumatic brain injury to help stratify children according to their risk. ${ }^{23,24}$ However, these studies did not suggest a definitive approach to management for a substantial proportion of children included in the guideline. For example, the Pediatric Emergency Care Applied Research Network (PECARN) rule suggested 
observation or computed tomography (CT) scan for $33 \%$ of their study population. ${ }^{23}$ A recent survey showed a wide variation in the practice pattern of Canadian pediatric emergency physicians for ordering skull radiography in young children with minor head trauma described in 11 clinical vignettes. ${ }^{25}$ The study also reported that about half of the respondents would change their management plan if a skull fracture was present.

The balance between the important complications associated with skull fracture (i.e., displaced or growing fracture, leptomeningeal cyst) and the rarity of skull fracture mandate a judicious use of radiology. We conducted a study to develop and validate a clinical decision rule to improve identification of skull fracture in children less than 2 years old with head trauma.

\section{Methods}

\section{Study design and population}

We conducted a multicentre, prospective cohort study in 3 tertiary care emergency departments in Montréal and Sherbrooke, Que.; 2 of the departments are participating sites of the Pediatric Emergency Research Canada group. Recruitment of patients occurred from Sept. 13, 2011, to Apr. 2, 2013, for the derivation phase and from Apr. 3, 2013, to Sept. 30, 2014, for the validation phase.

Eligible participants were all children less than 2 years old who were brought to the emergency department within 24 hours after experiencing any level of head trauma. We excluded children for whom a head CT scan was required because they had moderate or severe traumatic brain injury (Glasgow Coma Scale score $<14$ ) and those with minor head trauma who were at high risk of clinically important traumatic brain injury according to the PECARN rule (Glasgow Coma Scale score $<15$, altered level of consciousness or palpable skull fracture). ${ }^{23}$ Children for whom intentional injury or child abuse was suspected according to the treating physician were also excluded. Finally, we excluded children who had undergone a radiologic evaluation before being transferred to the study site, to minimize biases engendered by the fact that physicians knew that the patient had a fracture before completing the standardized report form.

\section{Outcome measures}

The primary outcome was the presence of any skull fracture diagnosed by radiography. Each study site used its own standardized protocol for radiography. They all included 4 views of the skull (anterior-posterior, lateral, Waters and Towne views). All radiologic exams were interpreted within 72 hours by a radiologist with expertise in pediatrics who was blinded to the independent variables except for the age of the patient. The choice of any skull fracture as the primary outcome was based on 3 criteria. First, studies have reported that skull fractures are highly associated with brain injury. ${ }^{25,8,9}$ Second, it is important not to miss a growing or displaced fracture. Finally, feasibility motivated our decision, because derivation of a clinical decision rule to identify only patients at risk of a growing skull fracture would need 25000 participants to identify 50 patients with the outcome of interest.

\section{Standardized assessment of patients}

Staff physicians in the emergency department or senior residents (fourth year or higher) certified in pediatrics, pediatric emergency medicine or emergency medicine assessed the patients. Before the start of the study, these physicians attended a 1-hour training session on assessing participants for independent variables and completing the standardized report form.

We identified potential predictor variables from a literature review and a consensus of 9 experts with backgrounds in pediatric emergency, adult emergency and neurosurgery. Through the literature review, we found 14 independent variables associated with an increased risk of skull fracture. ${ }^{4,520,22,26-32}$ The variables were related to demographic characteristics (age and sex); the accident (e.g., height of the fall, high-velocity impact, type of surface, fall from parent's arms or with the parent); the patient's symptoms (e.g., crying more than usual, bleeding, decrease in eating, hypotonia); and findings on physical examination (e.g., swelling or hematoma [consistency, width, localization], number and length of lacerations and pain on examination). The potential independent variables are listed in Appendix 1 (available at www.cmaj.ca/ lookup/suppl/doi:10.1503/cmaj.150540/-/DC1).

Children participating in the study were prospectively identified by the treating physicians. For each child who met the inclusion criteria, the treating physician completed a standardized report form after the initial physical examination and before radiologic evaluation. The decision to order skull radiography was at the physicians' discretion. Whenever possible, a nonrandom sample of patients was evaluated by a second rater within 30 minutes after the first evaluation.

Four weeks after the initial visit, a follow-up telephone call was performed by a research assistant to capture any subsequent medical care for all children who did not have a radiologic evaluation. The research assistant used a structured interview to enquire about the use of any health-related resources in the 4 weeks after the index visit. 


\section{Statistical analysis}

Initially, the prevalence of each risk factor was calculated. The interrater agreement was then measured in a convenience sample of 28 participants by pairs of physicians working independently using the $\kappa$ statistic $^{33}$ or intraclass correlation coefficient. ${ }^{34} \mathrm{We}$ calculated $95 \%$ confidence intervals (95\% CIs) for each proportion using the binomial (Clopper-Pearson) exact method based on the $\beta$ distribution. ${ }^{35}$ Because we expected to have few missing data, we considered them as negative.

For the derivation of the decision rule, we included risk factors that had a moderate to good interrater agreement $(\kappa$ value $>0.6)$ in a univariable analysis. We then included all risk factors with a $\kappa$ score greater than 0.6 in a recursive partitioning analysis..$^{36}$ For this analysis, we used the program KnowledgeSEEKER (version 6.0, Angoss Software International). The classification tree was obtained with use of the Salford Predictive Modeler software suite (version 7.0, Salford Systems). Prior probabilities of fracture were set to the ones observed in the derivation sample. The classification tree was constructed using the Gini splitting rule, and no stopping rule was used to construct a large tree. The optimal size of the classification tree was selected using the relative increase in cost com-

\begin{tabular}{|c|c|c|}
\hline \multirow[b]{2}{*}{ Characteristic } & \multicolumn{2}{|c|}{ Study cohort; no. (\%) of patients* } \\
\hline & $\begin{array}{l}\text { Derivation cohort } \\
\qquad n=811\end{array}$ & $\begin{array}{l}\text { Validation cohort } \\
\qquad n=856\end{array}$ \\
\hline Age, mo, median (IQR) & $8(5-12)$ & $8(5-12)$ \\
\hline Sex, male & $426(52.5)$ & $463(54.1)$ \\
\hline \multicolumn{3}{|l|}{ Study site } \\
\hline Hospital A & $586(72.3)$ & $610(71.3)$ \\
\hline Hospital B & $225(27.7)$ & $210(24.5)$ \\
\hline Hospital C & 0 & $40 \quad(4.7)$ \\
\hline Trauma due to a fall & $711(87.7)$ & $756(88.3)$ \\
\hline Fall from arms of a parent & $75 \quad(9.2)$ & $82(9.6)$ \\
\hline Fall in the stairs & $83(10.2)$ & $109(12.7)$ \\
\hline Radiologic evaluation & $291(35.9)$ & $354(41.4)$ \\
\hline Skull fracture & $49(6.0)$ & $44 \quad(5.1)$ \\
\hline Simple & 41 & 35 \\
\hline Diastasis $>4 \mathrm{~mm}$ & 5 & 1 \\
\hline Displaced fracture & 3 & 7 \\
\hline Ping-pong fracture & 0 & 1 \\
\hline \multicolumn{3}{|c|}{$\begin{array}{l}\text { Note: IQR = interquartile range. } \\
\text { *Unless stated otherwise. } \\
\text { tHospital A = Centre hospitalier universitaire (CHU) Sainte-Justine, B = Montréal Children's } \\
\text { Hospital, C = Hôpital Fleurimont (CHU Sherbrooke). }\end{array}$} \\
\hline
\end{tabular}

plexity. We evaluated the performance of the clinical decision rule by comparing the classification of each patient with his or her actual status for the primary outcome, which allowed us to calculate the sensitivity and specificity of the rule.

We calculated the sample size of the derivation cohort based on the desired CIs of the measurement of sensitivity. Based on an expected sensitivity of $95 \%$, the recruitment of 50 patients with the primary outcome was expected to provide a $95 \% \mathrm{CI}$ of $89 \%-100 \%$. Also, according to previously published methodologic standards for the development of clinical decision rules, there should be at least 10 outcome events per independent variable included in the decision rule. ${ }^{37,38}$ This approach limits the risk of overfitting the data. ${ }^{39}$ We planned to recruit about 850 patients per phase based on the expectation of a $6 \%$ risk of skull fracture.

For validation of the decision rule, we measured the sensitivity and specificity of the rule to detect skull fracture when applied to the validation cohort. The treating physicians remained blinded to the elements of the rule during the validation phase and were informed to continue their usual practice in the management of children with an isolated head trauma. For the sample size, we calculated that at least 40 patients with a skull fracture would be needed to provide a $95 \%$ CI of $87 \%-100 \%$ for the sensitivity measure.

\section{Ethics approval}

The project was approved by the research ethics boards at the 3 participating centres. Because of the study's observational design, parents of the recruited patients were required to give consent to a possible telephone follow-up call (verbal consent at one of the centres and written consent at the others).

\section{Results}

A total of 1667 children met the inclusion criteria; 811 (49 with skull fracture) were recruited during the derivation phase and 856 (44 with skull fracture) during the validation phase. Most of the patients were less than 1 year old, and in almost $90 \%$ of the cases the trauma was due to a fall (Table 1). Skull radiography was ordered for $645(38.7 \%)$ of the children (291 [35.9\%] in the derivation cohort, 354 [41.4\%] in the validation cohort). Of the remaining 1022 children, $97.0 \%$ (991 [507 in the derivation cohort and 484 in the validation cohort]) were followed up by telephone at 4 weeks. None of them had complications from their head injury.

Interrater agreement was good ( $\kappa$ or intraclass coefficient correlation $>0.60$ ) for most of the in- 
dependent variables associated with an increased risk of skull fracture (Table 2). However, some clinical signs were so uncommon that the response was the same for all 28 participants. Three of the variables were excluded because of their poor reliability, 3 independent variables were excluded. The association between independent variables and skull fracture in the derivation phase is shown in Appendix 2 (available at www.cmaj.ca/lookup/suppl/doi:10.1503/ cmaj.150540/-/DC1).

Recursive partitioning was used to derive a simple clinical decision rule to identify skull fracture (Figure 1). Parietal or occipital swelling or hematoma and age less than 2 months were predictors that accurately identified 94\% (95\% CI $83 \%-99 \%$ ) of the patients with skull fracture in the derivation cohort (Table 3). The specificity of the rule was calculated at $86 \%$ (95\% CI
84\%-89\%) in the derivation phase. Using the rule would have decreased the number of radiologic evaluations from 291 to 150 .

The baseline characteristics of the patients in the validation cohort were similar to those of patients in the derivation cohort, with the exception of the addition of a third study site (Table 1). When applied to the validation cohort, the clinical decision rule showed a sensitivity of $89 \%(95 \%$ CI $76 \%-95 \%)$ and a specificity of $87 \%$ (95\% CI $84 \%-89 \%$ ) (Table 3). Using the rule would have decreased the number of radiologic evaluations from 354 to 148 .

\section{Interpretation}

We have developed a clinical decision rule that identified about $90 \%$ of skull fractures among young children with head trauma who were not

Table 2: Interrater agreement for independent variables associated with increased risk of skull fracture

\begin{tabular}{|c|c|c|c|}
\hline Independent variable & Agreement & Intraclass correlation* & $\kappa$ value \\
\hline Age & $24 / 28$ & 0.997 (0.994 to 0.999$)$ & \\
\hline Age category & $28 / 28$ & & \\
\hline Sex & $28 / 28$ & & \\
\hline Bone fragility $\dagger$ & $27 / 28$ & & 0.65 (0.01 to 1.00$)$ \\
\hline Hypotonia & $28 / 28$ & & \\
\hline Dysmorphism & $27 / 28$ & & 0.65 (0.01 to 1.00$)$ \\
\hline Vague history & $24 / 28$ & & $-0.007(-0.15$ to -0.02$)$ \\
\hline Height of fall & $16 / 28$ & 0.25 (-0.12 to 0.57$)$ & \\
\hline Fall from parent's arm & $23 / 28$ & & 0.59 (0.26 to 0.91$)$ \\
\hline Fall in stairs & $27 / 28$ & & 0.89 (0.64 to 1.00$)$ \\
\hline High-velocity fall & $28 / 28$ & & \\
\hline Fall onto hard surface & $20 / 28$ & & 0.30 (-0.07 to 0.68$)$ \\
\hline Redness & $23 / 28$ & & 0.64 (0.35 to 0.93$)$ \\
\hline Presence of a bump & $24 / 28$ & & 0.67 (0.38 to 0.97$)$ \\
\hline Hematoma size & $21 / 28$ & 0.65 (0.37 to 0.82 ) & \\
\hline Hematoma $>2 \mathrm{~cm}$ & $25 / 28$ & & 0.64 (0.35 to 0.68$)$ \\
\hline Hematoma softness & $23 / 26 \ddagger$ & & $0.73 \quad(0.44$ to 1.00$)$ \\
\hline Localization of hematoma & $23 / 27$ & & $0.66 \quad(0.35$ to 0.97$)$ \\
\hline Non-frontal hematoma & $27 / 27$ & & \\
\hline Crying with palpation & $18 / 28$ & & 0.01 ( -0.30 to 0.33$)$ \\
\hline Laceration & $28 / 28$ & & \\
\hline Deformity & $27 / 28 \S$ & & \\
\hline Penetrating trauma & $28 / 28 \S$ & & \\
\hline Epistaxis & $28 / 28 \S$ & & \\
\hline Basal skull fracture & $28 / 28 \S$ & & \\
\hline \multicolumn{4}{|c|}{$\begin{array}{l}\text { *Intraclass correlation was measured only for variables with more than } 2 \text { choices. } \\
\text { tBone fragility was determined by the treating physician as any condition that increases the fragility of the bone (e.g., osteopenia, } \\
\text { osteogenesis imperfecta, rickets). } \\
\text { \#Missing data for } 2 \text { participants. } \\
\text { §First evaluator found no deformity, penetrating trauma, epistaxis or basal skull fracture sign on all patients. }\end{array}$} \\
\hline
\end{tabular}


at high risk of clinically important traumatic brain injury. The 2 predictors identified through recursive partitioning for the development of the rule were parietal or occipital swelling or hematoma and age less than 2 months. The sensitivity of the rule in the prospective validation phase was similar to the sensitivity in the derivation phase. Use of the rule would have decreased the overall the number of skull radiographs by about $60 \%$ in our study population.

Bin and associates ${ }^{40}$ reported a clinical score to predict skull fracture among children less than 2 years of age. Their clinical score was based on the age of the patient, and the size and location of the hematoma. They reported a sensitivity of $90 \%$ for skull fracture and a specificity of $78 \%$. Many characteristics of the study limited the usefulness of the score. First, most of the participants had signs and symptoms of brain injury that would mandate a head CT scan, which would have left only 82 patients with no indication for CT scan (only 14 fractures). Also, the complexity of remembering a score on 8 points might limit its use by emergency physicians.

Although we had a different outcome of interest, our study is comparable to a recent subanalysis of the PECARN database aiming to identify the association between characteristics of scalp hematoma and traumatic brain injury in children less than 2 years old who had no other symptoms or signs suggestive of traumatic brain injury. ${ }^{41}$ This later study reported an increased risk of clinically important traumatic brain injury among children less than 3 months and those with a non-frontal hematoma.

Many guidelines for the use of skull radiography in children have been proposed based on consensus of experts. The American Academy of

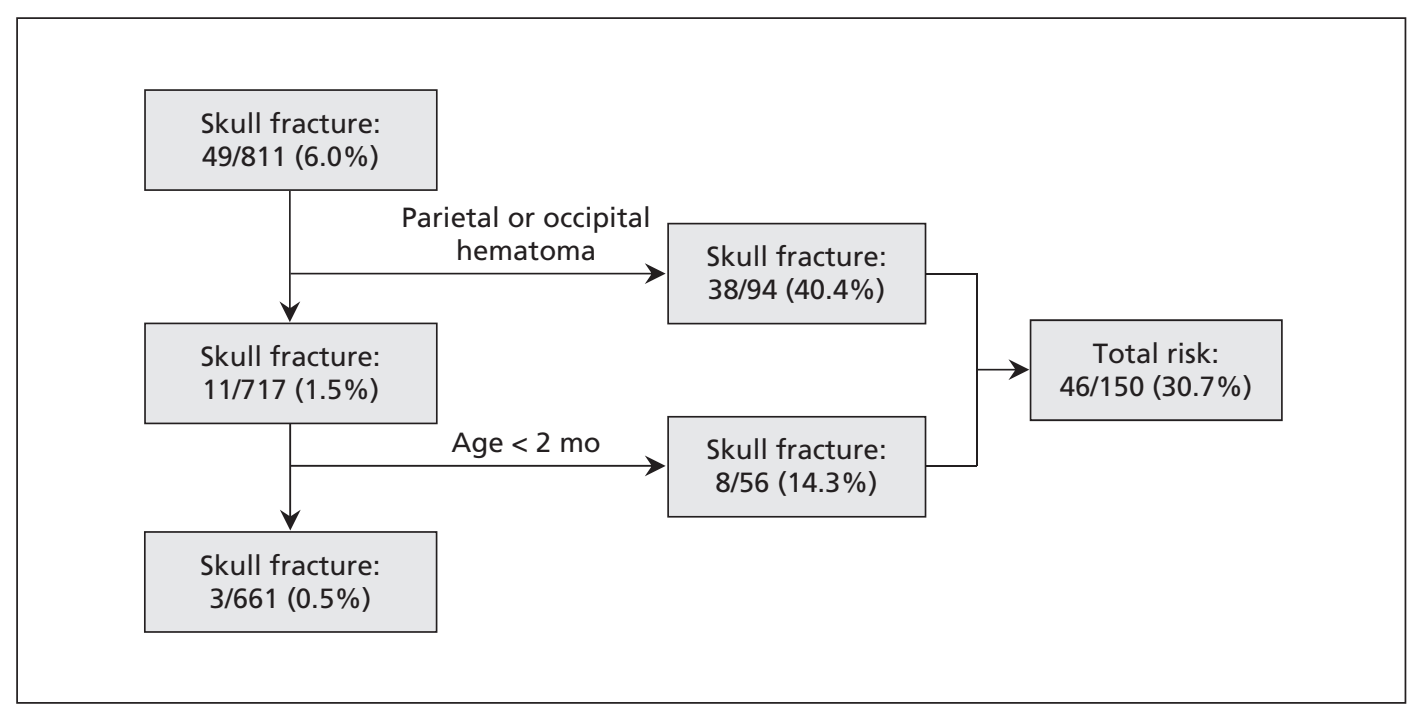

Figure 1: Recursive partitioning for the derivation of a clinical decision rule to identify skull fracture in a cohort of $\mathbf{8 1 1}$ children less than $\mathbf{2}$ years old with minor head trauma.

Table 3: Performance of the clinical decision rule to identify skull fracture in young children with minor head trauma

\begin{tabular}{|c|c|c|c|c|c|c|}
\hline \multirow[b]{2}{*}{ Result with rule } & \multicolumn{3}{|c|}{ Derivation cohort } & \multicolumn{3}{|c|}{ Validation cohort } \\
\hline & Fracture & No fracture & Total & Fracture & No fracture & Total \\
\hline Negative & 3 & 658 & 661 & 5 & 703 & 708 \\
\hline Total & 49 & 762 & 811 & 44 & 812 & 856 \\
\hline Specificity, \% (95\% Cl) & \multicolumn{2}{|c|}{$86(84-89)$} & & \multicolumn{2}{|c|}{$87(84-89)$} & \\
\hline Positive predictive value, $\%(95 \% \mathrm{Cl})$ & \multicolumn{2}{|c|}{$31(23-39)$} & & \multicolumn{2}{|c|}{$26(19-34)$} & \\
\hline Negative predictive value, $\%(95 \% \mathrm{Cl})$ & \multicolumn{2}{|c|}{$100(99-100)$} & & \multicolumn{2}{|c|}{$99(98-100)$} & \\
\hline Positive likelihood ratio $(95 \% \mathrm{Cl})$ & \multicolumn{2}{|c|}{$6.88(5.67-8.34)$} & & \multicolumn{2}{|c|}{$6.60(5.38-8.10)$} & \\
\hline Negative likelihood ratio $(95 \% \mathrm{Cl})$ & \multicolumn{2}{|c|}{$0.07(0.02-0.21)$} & & \multicolumn{2}{|c|}{$0.13(0.06-0.30)$} & \\
\hline
\end{tabular}


Pediatrics suggests that skull radiography be considered for children less than 2 years old with mild head trauma who are at intermediate risk of skull fracture, defined as higher force mechanism, large hematoma, fall onto hard surface, unwitnessed accident or vague history. ${ }^{20}$ The guideline from the National Institute for Clinical Excellence suggests skull radiography only for suspected inflicted head trauma or depressed skull fracture. ${ }^{21}$

We believe that use of our decision rule would allow better use of health care resources and avoid unnecessary referrals from physicians' offices to the emergency department for young children at low risk of fracture according to the rule. Also, better identification of skull fracture would improve management, because skull fracture has been shown to be an important factor when deciding whether to admit young children after head trauma. ${ }^{25,42}$ Finally, the application of the rule by triage nurses may improve the length of stay in the emergency departmet for eligible children. A new prospective study would be needed to evaluate applicability of the rule by triage nurses.

Four of the 5 missed fractures were in children less than 4 months old. Modifying the rule to include children 3 months old and younger would increase the sensitivity to $98 \%$ (95\% CI $88 \%-$ $100 \%$ ) and lower the specificity to $82 \%$ (95\% CI $79 \%-84 \%$ ) in the validation cohort. Use of the modified rule would have decreased the number of radiologic evaluations from 354 to 193 . The risk of fracture was 1 in 663 among the participants who were negative with the modified rule. However, the performance of the modified rule would need to be prospectively validated in another population.

\section{Limitations}

Our study has limitations. First, not all of the patients had a radiologic evaluation, so some skull fractures may have been missed. However, $97 \%$ of the children who did not have a radiologic evaluation were followed up after 4 weeks, and none of them had complications. Although this does not exclude skull fracture, it excludes complications secondary to skull fracture. Second, the rule was validated in tertiary care settings. This may have resulted in selection bias toward better validity and reliability of the decision rule. However, the number of physicians involved in the study $(>50)$ decreases this risk of bias. To account for that limitation, the rule would need to be validated in primary care settings. Third, because a number of different physicians evaluated the patients, we could not measure interrater reliability for 2 consistent raters. This was not considered in the calculation of the $\kappa$ values. Fourth, although it was a large study with more than 1600 participants, only 93 chil- dren had the primary outcome of skull fracture. This small number engendered large confidence intervals for the results and limits precision of the conclusions. Also, the number of patients was very low for the third study site. Fifth, the clinical decision rule was validated in the same sites as those used in the derivation phase. To be fully validated, the rule should be evaluated in different settings. This could be performed in an implementation study. Finally, the rule was not used by the treating physicians in the validation phase, and its impact on the radiography rate was not evaluated. This would need to be done in an implementation trial.

\section{Conclusion}

We developed a clinical decision rule that identified about $90 \%$ of skull fractures among children less than 2 years old who had acute head trauma with no immediate indication for head tomography. The 2 predictors identified through recursive partitioning for the development of the rule were parietal or occipital swelling or hematoma and age less than 2 months. Use of the rule would have decreased the overall the number of skull radiographs by about $60 \%$ in our study population. Even though the rule seems simple to use, an implementation study conducted in multiple settings would be necessary to ensure robust external validity and proper application of the rule in different clinical settings.

\section{References}

1. Cassidy JD, Carroll LJ, Peloso PM, et al. Incidence, risk factors and prevention of mild traumatic brain injury: results of the WHO Collaborating Centre Task Force on Mild Traumatic Brain Injury. J Rehabil Med 2004;(Suppl):28-60.

2. Greenes DS, Schutzman SA. Clinical indicators of intracranial injury in head-injured infants. Pediatrics 1999;104:861-7.

3. Schunk JE, Rodgerson JD, Woodward GA. The utility of head computed tomographic scanning in pediatric patients with normal neurologic examination in the emergency department. Pediatr Emerg Care 1996;12:160-5

4. Quayle KS, Jaffe DM, Kuppermann N, et al. Diagnostic testing for acute head injury in children: When are head computed tomography and skull radiographs indicated? Pediatrics 1997;99:E11.

5. Gruskin KD, Schutzman SA. Head trauma in children younger than 2 years: Are there predictors for complications? Arch Pediatr Adolesc Med 1999;153:15-20.

6. Stewart G, Meert K, Rosenberg N. Trauma in infants less than three months of age. Pediatr Emerg Care 1993;9:199-201.

7. Rivara FP. Childhood injuries. III: epidemiology of non-motor vehicle head trauma. Dev Med Child Neurol 1984;26:81-7.

8. Chan KH, Yue CP, Mann KS. The risk of intracranial complications in pediatric head injury. Results of multivariate analysis. Childs Nerv Syst 1990;6:27-9.

9. Shane SA, Fuchs SM. Skull fractures in infants and predictors of associated intracranial injury. Pediatr Emerg Care 1997;13:198203.

10. Mann KS, Chan KH, Yue CP. Skull fractures in children: their assessment in relation to developmental skull changes and acute intracranial hematomas. Childs Nerv Syst 1986;2:258-61.

11. Hofman PA, Nelemans P, Kemerink GJ, et al. Value of radiological diagnosis of skull fracture in the management of mild head injury: meta-analysis. J Neurol Neurosurg Psychiatry 2000;68:416-22.

12. Taveras JM, Ransohoff J. Leptomeningeal cysts of the brain following trauma with erosion of the skull; a study of seven cases treated by surgery. J Neurosurg 1953;10:233-41. 
13. Ersahin Y, Gülmen V, Palali I, et al. Growing skull fractures (craniocerebral erosion). Neurosurg Rev 2000;23:139-44.

14. Ersahin Y, Mutluer S, Mirzai H, et al. Pediatric depressed skull fractures: analysis of 530 cases. Childs Nerv Syst 1996;12:323-31.

15. Gupta SK, Reddy NM, Khosla VK, et al. Growing skull fractures: a clinical study of 41 patients. Acta Neurochir (Wien) 1997;139:928-32.

16. Pezzotta S, Silvani V, Gaetani P, et al. Growing skull fractures of childhood. Case report and review of 132 cases. J Neurosurg Sci 1985;29:129-35.

17. Sacchetti A, Senula G, Strickland J, et al. Procedural sedation in the community emergency department: initial results of the ProSCED registry. Acad Emerg Med 2007;14:41-6.

18. Sanford RA. Prevention of growing skull fractures: report of 2 cases. J Neurosurg Pediatr 2010;5:213-8.

19. Macgregor DM, McKie L. CT or not CT - that is the question. Whether "tis better to evaluate clinically and $\mathrm{x}$ ray than to undertake a CT head scan! Emerg Med J 2005;22:541-3.

20. Schutzman SA, et al. Evaluation and management of children younger than two years old with apparently minor head trauma: proposed guidelines. Pediatrics 2001;107:983-93.

21. Head injury. Triage, assessment, investigation and early management of head injury in infants, children and adults. London (UK): National Collaborating Centre for Acute Care; 2007.

22. Beaudin M, Saint-Vil D, Ouimet A, et al. Clinical algorithm and resource use in the management of children with minor head trauma. J Pediatr Surg 2007;42:849-52.

23. Kuppermann N, Holmes JF, Dayan PS, et al. Identification of children at very low risk of clinically-important brain injuries after head trauma: a prospective cohort study. Lancet 2009;374:1160-70.

24. Osmond MH, Klassen TP, Wells GA, et al.; Pediatric Emergency Research Canada (PERC) Head Injury Study Group. CATCH: clinical decision rule for the use of computed tomography in children with minor head injury. CMAJ 2010;182:341-8.

25. Carrière $\mathrm{B}$, Clement $\mathrm{K}$, Gravel J. Variation in the use of skul radiographs by emergency physicians in young children with minor head trauma. CJEM 2014;16:281-7.

26. Boulis ZF, Dick R, Barnes NR. Head injuries in childrenaetiology, symptoms, physical findings and $\mathrm{x}$-ray wastage. $\mathrm{Br} J$ Radiol 1978;51:851-4.

27. Leonidas JC, Ting W, Binkiewicz A, et al. Mild head trauma in children: When is a roentgenogram necessary? Pediatrics 1982; 69:139-43.

28. Dunning J, Daly JP, Lomas JP, et al. Derivation of the children's head injury algorithm for the prediction of important clinical events decision rule for head injury in children. Arch Dis Child 2006;91:885-91

29. Browning JG, Reed MJ, Wilkinson AG, et al. Imaging infants with head injury: effect of a change in policy. Emerg Med $J$ 2005;22:33-6.

30. Early Management of patients with a head injury: a national clinical guideline. Edinburgh: Scottish Intercollegiate Guidelines Network; 2009

31. Greenes DS, Schutzman SA. Infants with isolated skull fracture: What are their clinical characteristics, and do they require hospitalization? Ann Emerg Med 1997;30:253-9.
32. Greenes DS, Schutzman SA. Clinical significance of scalp abnormalities in asymptomatic head-injured infants. Pediatr Emerg Care 2001;17:88-92.

33. Landis JR, Koch GG. The measurement of observer agreement for categorical data. Biometrics 1977;33:159-74.

34. Brennan RL, Prediger DJ. Coefficient kappa: some uses, misuses, and alternatives. Educ Psychol Meas 1981;41:687-99.

35. Reiczigel J. Confidence intervals for the binomial parameter: some new considerations. Stat Med 2003;22:611-21.

36. Ciampi A, Hogg SA, McKinney S, et al. RECPAM: a computer program for recursive partition and amalgamation for censored survival data and other situations frequently occurring in biostatistics. I. Methods and program features. Comput Methods Programs Biomed 1988;26:239-56.

37. Stiell IG, Wells GA. Methodologic standards for the development of clinical decision rules in emergency medicine. Ann Emerg Med 1999;33:437-47.

38. Wasson JH, Sox HC, Neff RK, et al. Clinical prediction rules. Applications and methodological standards. $N$ Engl J Med 1985;313:793-9.

39. Concato J, Feinstein AR, Holford TR. The risk of determining risk with multivariable models. Ann Intern Med 1993;118:201-10.

40. Bin SS, Schutzman SA, Greenes DS. Validation of a clinical score to predict skull fracture in head-injured infants. Pediatr Emerg Care 2010;26:633-9.

41. Dayan PS, Holmes JF, Schutzman S, et al. Risk of traumatic brain injuries in children younger than 24 months with isolated scalp hematomas. Ann Emerg Med 2014;64:153-62.

42. Mannix R, et al. Isolated skull fractures: trends in management in US pediatric emergency departments. Ann Emerg Med 2013; 62:327-31.

Affiliations: Départements de pédiatrie (Gravel, Gouin), chirurgie (Crevier) and radiologie (Décarie), Centre hospitalier universitaire (CHU) Sainte-Justine, Université de Montréal; Department of Pediatrics (Chalut), Montréal Children's Hospital, McGill University, Montréal, Que.; Département d'urgence (Elazhary), Hôpital Fleurimont (CHU Sherbrooke), Université de Sherbrooke, Sherbrooke, Que.; Centre de recherche du CHU Sainte-Justine (Mâsse), Université de Montréal, Montréal, Que.

Contributors: Jocelyn Gravel conceived the study and designed the trial. Jocelyn Gravel, Serge Gouin and Benoît Mâsse obtained funding for the study. All of the authors contributed to the study design. Dominic Chalut, Nicolas Elazhary and Jocelyn Gravel were responsible for data collection at their sites. Jocelyn Gravel and Benoît Mâsse performed the data analysis. Jocelyn Gravel drafted the manuscript, and all of the authors contributed to its revision. All of the authors approved the final version to be published and agreed to be guarantors of the work.

Funding: The study was funded by a grant from the Fond de recherche du Québec - Santé. 